\title{
Impact of environmental pollution and weather changes on the incidence of ST-elevation myocardial infarction
}

European Journal of Preventive Cardiology $0(0) 1-8$

(C) The European Society of Cardiology 2020 Article reuse guidelines: sagepub.com/journals-permissions DOI: $10.1177 / 2047487320928450$ journals.sagepub.com/home/cpr

(SAGE

\author{
Giuseppe Biondi-Zoccai ${ }^{1,2}$, Giacomo Frati ${ }^{1,3}$, \\ Achille Gaspardone ${ }^{4}$, Enrica Mariano ${ }^{5}$, Alessandro D Di Giosa ${ }^{6}$, \\ Andrea Bolignano ${ }^{6}$, Angela Dei Giudici ${ }^{7}$, Simone Calcagno ${ }^{7}$, \\ Massimiliano Scappaticci ${ }^{7}$, Sebastiano Sciarretta ${ }^{1,3}$, \\ Valentina Valenti ${ }^{7}$, Rebecca Casati ${ }^{7}$, Giuseppe Visconti ${ }^{8}$, \\ Maria Penco9, Maria B Giannico ${ }^{4}$, Mariangela Peruzzi $i^{1,2}$, \\ Elena Cavarretta ${ }^{1,2}$, Simone Budassi ${ }^{5}$, Joseph Cosma ${ }^{5}$, \\ Massimo Federici ${ }^{10}$, Leonardo Roever ${ }^{11}$, Francesco Romeo ${ }^{5}$ \\ and Francesco Versaci ${ }^{7}$
}

\begin{abstract}
Background: Environmental pollution and weather changes unfavorably impact on cardiovascular disease. However, limited research has focused on ST-elevation myocardial infarction (STEMI), the most severe yet distinctive form of acute coronary syndrome.

Methods and results: We appraised the impact of environmental and weather changes on the incidence of STEMI, analysing the bivariate and multivariable association between several environmental and atmospheric parameters and the daily incidence of STEMI in two large Italian urban areas. Specifically, we appraised: carbon monoxide (CO), nitrogen dioxide (NO2), nitric oxide (NOX), ozone, particulate matter smaller than $10 \mu \mathrm{m}$ (PMI0) and than $2.5 \mu \mathrm{m}$ (PM2.5), temperature, atmospheric pressure, humidity and rainfall. A total of 4285 days at risk were appraised, with 3473 cases of STEMI. Specifically, no STEMI occurred in 1920 (44.8\%) days, whereas one or more occurred in the remaining 2365 (55.2\%) days. Multilevel modelling identified several pollution and weather predictors of STEMI. In particular, concentrations of $\mathrm{CO}(p=0.024)$, NOX $(p=0.039)$, ozone $(p=0.003)$, PMIO $(p=0.033)$ and PM2.5 $(p=0.042)$ predicted STEMI as early as three days before the event, as well as subsequently, and NO predicted STEMI one day before $(p=0.010)$, as well as on the same day. A similar predictive role was evident for temperature and atmospheric pressure (all $p<0.05$ ). Conclusions: The risk of STEMI is strongly associated with pollution and weather features. While causation cannot yet be proven, environmental and weather changes could be exploited to predict STEMI risk in the following days.
\end{abstract}

\section{Keywords}

Acute myocardial infarction, environment, pollution, ST-elevation myocardial infarction, weather

Received 25 March 2020; accepted I May 2020

\footnotetext{
'Department of Medical-Surgical Sciences and Biotechnologies, Sapienza University of Rome, Italy

${ }^{2}$ Mediterranea Cardiocentro, Italy

${ }^{3}$ IRCCS NEUROMED, Italy

${ }^{4}$ Division of Cardiology, Ospedale S. Eugenio, Italy

${ }^{5}$ Division of Cardiology, Tor Vergata University, Italy

${ }^{6}$ ARPA Lazio, Italy

${ }^{7}$ Division of Cardiology, Santa Maria Goretti Hospital, Italy

${ }^{8}$ ASL Latina, Italy
}

\footnotetext{
${ }^{9}$ Division of Cardiology, University of L’Aquila, Italy

${ }^{10}$ Department of Systems Medicine, Tor Vergata University, Italy

"Department of Clinical Research, Federal University of Uberlandia, Brazil

Corresponding author:

Giuseppe Biondi-Zoccai, Department of Medical-Surgical Sciences and Biotechnologies, Sapienza University of Rome, Corso della Repubblica 79, 04100 Latina, Italy.

Email: giuseppe.biondizoccai@uniromal.it
} 


\section{Introduction}

Weather and environmental pollution represent two atherothrombotic risk factors which impact individuals at large by means of population effect. ${ }^{1-8}$ Indeed, several studies have highlighted, for instance, how lower temperatures are associated with an increased risk of acute cardiovascular events, ranging from sudden death to unstable angina. ${ }^{9-12}$ Similarly, it is well established how the outdoor concentration of several pollutants, such as fine particulate matter, is associated with cardiovascular morbidity and mortality. ${ }^{13}$ Moreover, it is increasingly clear that the consequences of anthropogenic activities, particularly atmospheric emissions, have both direct and indirect adverse impacts upon cardiovascular health. ${ }^{11,12,14,15}$ The public health relevance of a trigger is dependent not only on the individual relative risk but also on the prevalence of this risk factor within the population. Some risk factors, such as cocaine use, have a high individual acute myocardial infarction (AMI) risk. In contrast, environmental triggers expose the entire population and have a considerable public health impact despite a small individual relative risk.

Several recent research efforts have aimed at disentangling the mechanistic impact of pollution and weather features on atherothrombosis, but few reports have focused explicitly on the interplay between these two separate yet interactive factors. ${ }^{6}$ Of note, there is conflicting evidence on the role of different pollutants, given the interaction between the concentration of many of them. ${ }^{16,17}$ On top of this, the independent and multiplicative impact of ambient weather features on pollution and the ensuing risk of the most severe form of atherothrombosis, that is, acute ST-elevation myocardial infarction (STEMI), remains hitherto debated. ${ }^{7,18}$

We aimed at appraising the impact of pollution and weather on the risk of STEMI in contemporary practice, focusing on STEMI risk acutely and in the days following specific exposures to pollutants and weather changes.

\section{Methods}

This is a retrospective analysis of anonymized data on the incidence of STEMI between 2017 and 2019 in three high-volume centres with $24 / 7$ primary percutaneous coronary intervention (PCI) services in Lazio, Italy. ${ }^{19}$ Specifically, the number of daily STEMI cases was systematically collected per centre, and matched with data on local weather provided by Italian Air Force, Rome, Italy, and data on local pollution provided by Agenzia Regionale per la Protezione dell'Ambiente (ARPA) of Lazio, also in Rome, Italy.
While our data collection did not include all patients at risk in the Lazio region, all cases treated in the three high-volume centres participating in the study were included, without any exclusion. Accordingly, changes in population at risk could not be accounted for directly.

In terms of environment, the following pollutants were systematically collected, with several daily measurements: carbon monoxide $(\mathrm{CO})$, nitrogen dioxide (NO2), nitric oxide (NOX), ozone (O3), fine particulate matter (i.e. with mean aerodynamic diameter $<2.5 \mu \mathrm{m}$ in diameter (PM2.5)) and particulate matter with mean aerodynamic diameter $<10 \mu \mathrm{m}$ in diameter (inclusive of PM2.5 (PM10)), and all expressed as $\mu \mathrm{m} / \mathrm{m}^{3}$, with the exception of $\mathrm{CO}$, which mas measured in $\mathrm{mg} / \mathrm{m}^{3}{ }^{20}$

Accordingly, per-centre and per-day minimum, maximum, mean and change estimates for all the above pollutants were collected. In terms of weather, the following features were systematically collected as previously specified: temperature $\left({ }^{\circ} \mathrm{C}\right)$, atmospheric pressure, humidity $(\%)$ and rainfall $(\mathrm{mm}) .{ }^{18}$ Similarly, per-centre and per-day minimum, maximum, mean and change estimates for all the above weather features were collected, with the exception of rainfall. We explicitly aimed at appraising the impact of pollution and weather features on same day STEMI, as well as STEMI occurring one, two or three days afterwards. Additional exploratory analyses focused on the impact of environmental pollution and weather features on the risk of STEMI four, five, six, seven, 14 and 30 days later, as well as subgroup analyses focusing on percentre and per-season effects.

Descriptive analysis was based on computing mean \pm standard deviation, as well as coefficient of variation (i.e. standard deviation/mean). After appraising between-variable correlations by visual inspection of heatmaps and dendrograms, ${ }^{21}$ inferential analysis was based first on bivariate analysis using a mixed effect model with Poisson likelihood and log link, to account for centre-wise clustering. ${ }^{18}$ Models with and without quadratic terms were tested separately, to appraise the impact of non-linear effects. Computations were performed with Stata 13 (StataCorp, College Station, Texas, USA) and $\mathrm{R}$ 3.5.3 (R Foundation for Statistical Computing, Vienna, Austria).

\section{Results}

A total of 4285 days at risk were appraised with 3473 cases of STEMI (Table 1). Specifically, no STEMI occurred in $1920(44.8 \%)$ days, whereas one case occurred in $1526(35.6 \%)$ days, two cases in 618 $(14.4 \%)$ days, and three or more in 221 (5.2\%). Descriptive analysis highlighted significant variability in pollution and weather features, as shown by 
Table I. Descriptive analysis.

\begin{tabular}{lcl}
\hline & $\begin{array}{l}n(\%) \text { or } \\
\text { mean } \pm \text { standard } \\
\text { feviation }\end{array}$ & $\begin{array}{l}\text { Coefficient } \\
\text { of variation }\end{array}$ \\
\hline Daily PCI & & \\
0 & $1920(44.8)$ & - \\
I & $1526(35.6)$ & - \\
2 & $618(14.4)$ & - \\
3 or more & $221(5.2)$ & - \\
Carbon monoxide, $\mu \mathrm{m} / \mathrm{m}^{3}$ & $0.61 \pm 0.34$ & $55.7 \%$ \\
Nitrogen dioxide, $\mu \mathrm{m} / \mathrm{m}^{3}$ & $35.57 \pm 15.73$ & $44.1 \%$ \\
Nitric oxide, $\mu \mathrm{m} / \mathrm{m}^{3}$ & $63.22 \pm 44.08$ & $69.8 \%$ \\
Ozone, $\mu \mathrm{m} / \mathrm{m}^{3}$ & $52.02 \pm 20.73$ & $39.8 \%$ \\
PMI0, $\mu \mathrm{m} / \mathrm{m}^{3}$ & $26.92 \pm 12.69$ & $47.2 \%$ \\
PM2.5, $\mu \mathrm{m} / \mathrm{m}^{3}$ & $17.41 \pm 11.17$ & $64.4 \%$ \\
Temperature, ${ }^{\circ} \mathrm{C}$ & $14.29 \pm 6.96$ & $47.9 \%$ \\
Atmospheric pressure, ATM & $1014.94 \pm 6.96$ & $46.4 \%$ \\
Humidity, $\%$ & $70.87 \pm 12.78$ & $18.0 \%$ \\
Rainfall, $\mathrm{mm}$ & $2.32 \pm 6.96$ & $300.0 \%$ \\
\hline
\end{tabular}

${ }^{\mathrm{a} C}$ Computed using mean - 1000.

ATM: atmospheric pressure; $\mathrm{PCl}$ : percutaneous coronary intervention; PMI0: particulate matter with a diameter between $2.5 \mu \mathrm{m}$ and $10 \mu \mathrm{m}$; PM2.5: particulate matter with a diameter less than $2.5 \mu \mathrm{m}$ coefficient of variations ranging from $18 \%$ to $300 \%$. Most interestingly, weather and pollution features were significantly correlated (Supplementary Material Figures $1 \mathrm{~S}$ and Figure $2 \mathrm{~S}$ online). In particular, O3 was significantly and positively associated with temperature.

Multilevel modelling identified several pollution and weather predictors of STEMI, occurring either on the same day or on the following ones (Tables 2 and 3; Figure 1). Concentrations of CO $(p=0.024)$, NOX $(p=0.039), \mathrm{O} 3 \quad(p=0.003), \mathrm{PM} 10 \quad(p=0.033)$ and PM2.5 $(p=0.042)$ predicted STEMI as early as three days before the event, as well subsequently, and NO predicted STEMI one day before $(p=0.010)$, as well as on the same day. A similar significant role was evident for temperature and atmospheric pressure (all $p<0.05$ ). Notably, O3, as well as temperature and atmospheric pressure, was inversely associated with the risk of STEMI, as days with high O3 concentration, high temperature and high atmospheric pressure were associated with a lower risk of STEMI on the same day or on the following ones (Figure 2).

Associations were not linear in most cases, but curvilinear instead, as demonstrated by the presence of

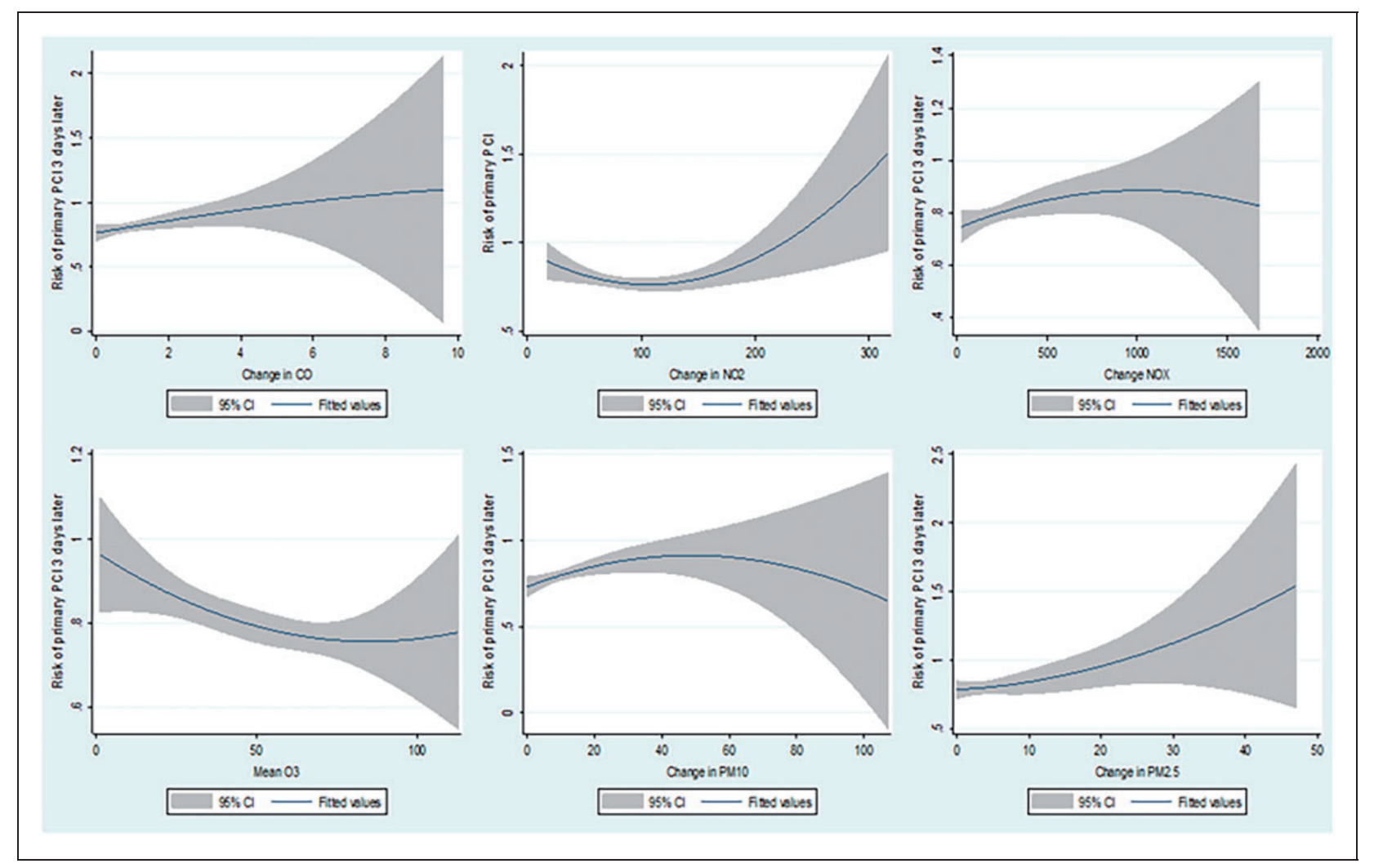

Figure I. Association between environmental pollution and weather features on the risk of ST-elevation myocardial infarction treated with primary percutaneous coronary intervention.

$\mathrm{Cl}$ : confidence interval; $\mathrm{CO}$ : carbon monoxide; NO2: nitric dioxide; NOX: nitric oxide; O3: ozone; PMI0: particulate matter with a diameter between $2.5 \mu \mathrm{m}$ and $10 \mu \mathrm{m}$; PM2.5: particulate matter with a diameter less than $2.5 \mu \mathrm{m}$ 


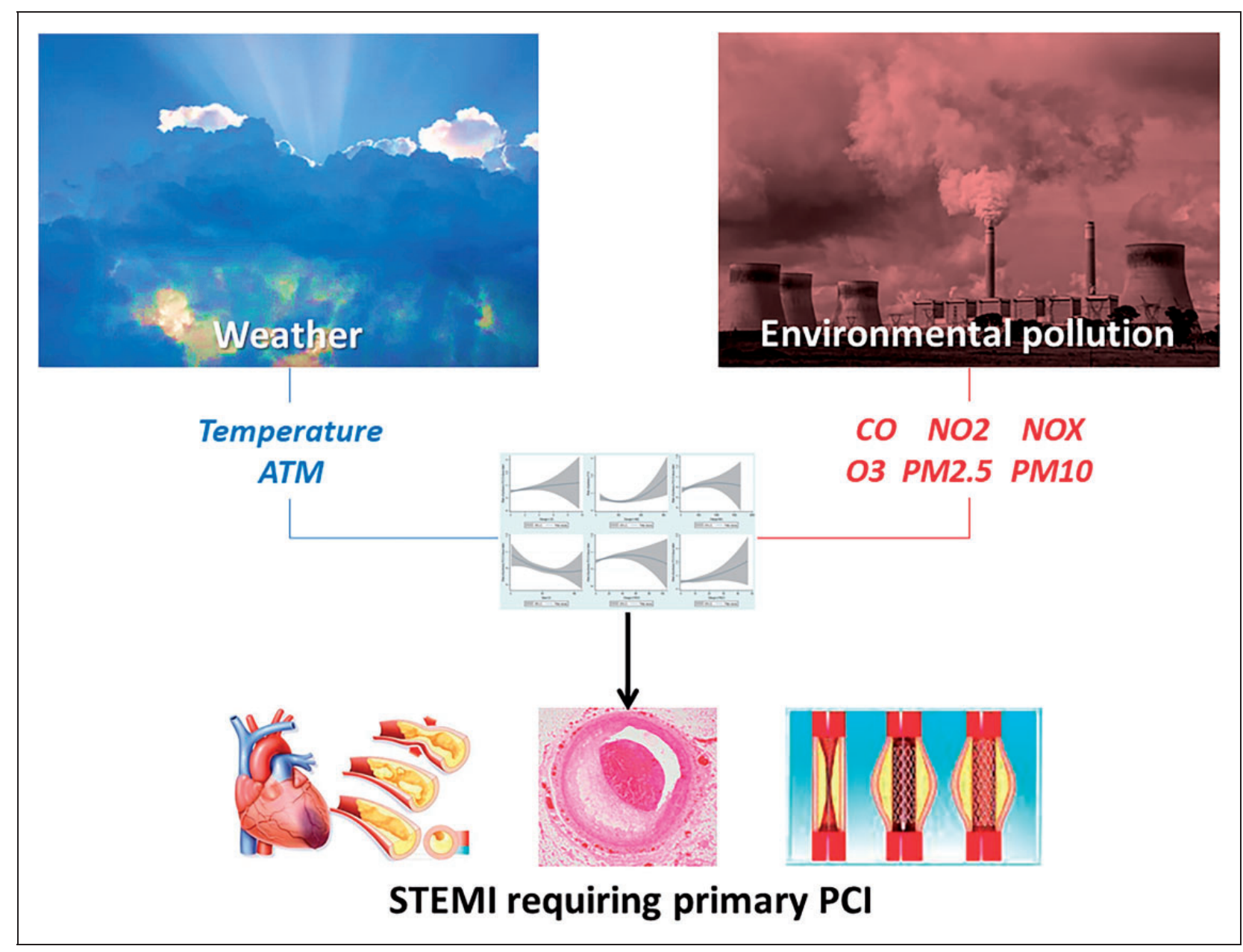

Figure 2. Graphical illustration summarizing the main study findings.

ATM: atmospheric pressure; CO: carbon monoxide; NO2: nitric dioxide; NOX: nitric oxide; O3: ozone; PCl: percutaneous coronary intervention; PMI0: particulate matter with a diameter between $2.5 \mu \mathrm{m}$ and $10 \mu \mathrm{m}$; PM2.5: particulate matter with a diameter less than $2.5 \mu \mathrm{m}$; STEMI: ST-elevation myocardial infarction

significant quadratic terms and also shown by visual inspection of quadratic prediction plots. This held true for the association between $\mathrm{CO}, \mathrm{NO} 2$ and NOX with same-day STEMI, as well as for the association between NO2 with STEMI occurring one day later, and for the association between temperature and atmospheric pressure with STEMI occurring two days later.

When exploring the impact of weather and environmental features on the risk of STEMI four, five, six, seven, 14 and 30 days later, we found that several of the features already impacting at short-term were also impactful subsequently (Supplementary Table 1S), and this held true for all of them, from $\mathrm{CO}$ to $\mathrm{NO} 2$, NOX, O3, PM10 and PM2.5. Conversely, pollutants were not homogeneously impactful in all participating centres (Supplementary Table 2S), suggesting that additional geographic factors (e.g. proximity to the sea, altitude, crowding and traffic) may be mechanistically related to STEMI risk. Finally, seasonspecific analyses suggested that most of the biologic effect of pollution and climate was evident in spring, summer and fall.

\section{Discussion}

Despite ongoing developments in the diagnosis, prevention, treatment and rehabilitation of AMI, several unmet needs remain. Accordingly, the overall impact of weather change on cardiovascular disease and particularly incident AMI is still unclear and will be the net result of several, sometimes divergent, effects and developments. ${ }^{22}$ Due to a decrease in cold days, there may be a drop in cold-related AMI, but this effect may be mitigated because AMI risk is mainly related to short-term major temperature changes, whereas 
Table 2. Exploratory inferential analysis.

\begin{tabular}{|c|c|c|c|c|}
\hline \multirow[b]{2}{*}{ Daily environmental or weather feature } & \multicolumn{4}{|l|}{ Incidence } \\
\hline & Same day & Day + I & Day +2 & Day +3 \\
\hline \multicolumn{5}{|l|}{ Carbon monoxide } \\
\hline Minimum & $p=0.02 I^{\mathrm{a}}$ & $p=0.434$ & $p=0.575$ & $p=0.432$ \\
\hline Maximum & $p=0.012^{a}$ & $p=0.179$ & $p=0.632$ & $p=0.029$ \\
\hline Mean & $p=0.016$ & $p=0.060$ & $p=0.388$ & $p=0.107$ \\
\hline Change & $p=0.008^{\mathrm{a}}$ & $p=0.139$ & $p=0.288$ & $p=0.024$ \\
\hline \multicolumn{5}{|l|}{ Nitrogen dioxide } \\
\hline Minimum & $p=0.048^{\mathrm{a}}$ & $p=0.065$ & $p=0.295$ & $p=0.760$ \\
\hline Maximum & $p=0.027$ & $p=0.010^{\mathrm{a}}$ & $p=0.509$ & $p=0.163$ \\
\hline Mean & $p=0.107$ & $p=0.021^{\mathrm{a}}$ & $p=0.524$ & $p=0.098$ \\
\hline Change & $p=0.020$ & $p=0.016^{\mathrm{a}}$ & $p=0.416$ & $p=0.178$ \\
\hline \multicolumn{5}{|l|}{ Nitric oxide } \\
\hline Minimum & $p=0.011^{\mathrm{a}}$ & $p=0.207$ & $p=0.206$ & $p=0.156$ \\
\hline Maximum & $p=0.125$ & $p=0.290$ & $p=0.263$ & $p=0.042$ \\
\hline Mean & $p=0.063$ & $p=0.196$ & $p=0.354$ & $p=0.039$ \\
\hline Change & $p=0.124$ & $p=0.309$ & $p=0.243$ & $p=0.043$ \\
\hline \multicolumn{5}{|l|}{ Ozone } \\
\hline Minimum & $p=0.126$ & $p=0.325$ & $p=0.360$ & $p=0.068$ \\
\hline Maximum & $p=0.002$ & $p=0.001$ & $p=0.002$ & $p=0.003$ \\
\hline Mean & $p=0.028$ & $p=0.011$ & $p=0.019$ & $p=0.003$ \\
\hline Change & $p=0.003$ & $p=0.004$ & $p=0.007$ & $p=0.031$ \\
\hline \multicolumn{5}{|l|}{ PMIO } \\
\hline Minimum & $p=0.578$ & $p=0.366$ & $p=0.435$ & $p=0.183$ \\
\hline Maximum & $p=0.261$ & $p=0.751$ & $p=0.075$ & $p=0.033$ \\
\hline Mean & $p=0.339$ & $p=0.735$ & $p=0.25 I$ & $p=0.104$ \\
\hline Change & $p=0.012$ & $p=0.228$ & $p=0.059$ & $p=0.018$ \\
\hline \multicolumn{5}{|l|}{ PM2.5 } \\
\hline Minimum & $p=0.175$ & $p=0.552$ & $p=0.205$ & $p=0.136$ \\
\hline Maximum & $p=0.387$ & $p=0.654$ & $p=0.673$ & $p=0.281$ \\
\hline Mean & $p=0.179$ & $p=0.438$ & $p=0.328$ & $p=0.079$ \\
\hline Change & $p=0.267$ & $p=0.240$ & $p=0.667$ & $p=0.042$ \\
\hline \multicolumn{5}{|l|}{ Temperature } \\
\hline Minimum & $p=0.055$ & $p=0.234$ & $p=0.222$ & $p=0.294$ \\
\hline Maximum & $p=0.008$ & $p=0.012$ & $p=0.007$ & $p=0.031$ \\
\hline Mean & $p=0.001$ & $p=0.006$ & $p=0.003$ & $p=0.004$ \\
\hline Change & $p=0.012$ & $p=0.004$ & $p=0.002^{a}$ & $p=0.015$ \\
\hline \multicolumn{5}{|l|}{ Atmospheric pressure } \\
\hline Minimum & $p=0.578$ & $p=0.788$ & $p=0.417$ & $p=0.095$ \\
\hline Maximum & $p=0.707$ & $p=0.264$ & $p=0.218$ & $p=0.030$ \\
\hline Mean & $p=0.389$ & $p=0.620$ & $p=0.869$ & $p=0.056$ \\
\hline Change & $p=0.192$ & $p=0.088$ & $p=0.023^{a}$ & $p=0.410$ \\
\hline \multicolumn{5}{|l|}{ Humidity } \\
\hline Minimum & $p=0.604$ & $p=0.287$ & $p=0.096$ & $p=0.130$ \\
\hline Maximum & $p=0.111$ & $p=0.384$ & $p=0.225$ & $p=0.206$ \\
\hline Mean & $p=0.201$ & $p=0.169$ & $p=0.109$ & $p=0.420$ \\
\hline Change & $p=0.806$ & $p=0.228$ & $p=0.07 I$ & $p=0.451$ \\
\hline Rainfall & $p=0.480$ & $p=0.798$ & $p=0.169$ & $p=0.413$ \\
\hline
\end{tabular}

ancluding significant quadratic term.

PMI0: particulate matter with a diameter between $2.5 \mu \mathrm{m}$ and $10 \mu \mathrm{m}$; PM2.5: particulate matter with a diameter less than $2.5 \mu \mathrm{m}$

global warming is characterized by a small, long-term temperature increase.

It is now evident that weather and pollution can also impact on the risk of atherothrombosis in apparently healthy subjects who are, however, prone to coronary instability, by modulating inflammation, thrombosis, vasoreactivity and many other pathophysiologic pathways. ${ }^{11,12,14,15,23}$ Several studies have focused on the 
Table 3. Detailed inferential analysis. ${ }^{a}$

\begin{tabular}{|c|c|c|c|c|c|}
\hline Timing & $\begin{array}{l}\text { Daily environmental } \\
\text { or weather feature }\end{array}$ & Specifics & $\begin{array}{l}\text { Point } \\
\text { estimate }\end{array}$ & $\begin{array}{l}95 \% \text { confidence } \\
\text { interval }\end{array}$ & $P$ \\
\hline \multirow[t]{12}{*}{ Same day } & \multirow[t]{4}{*}{ Carbon monoxide } & Minimum & $2.486^{\mathrm{b}}$ & $1.150-5.376^{\mathrm{b}}$ & 0.021 \\
\hline & & Maximum & $1.170^{\mathrm{b}}$ & $1.036-1.322^{b}$ & 0.012 \\
\hline & & Mean & 1.187 & $1.033-1.365$ & 0.016 \\
\hline & & Change & $1.184^{\mathrm{b}}$ & $1.044-1.343^{b}$ & 0.008 \\
\hline & \multirow[t]{3}{*}{ Nitrogen dioxide } & Minimum & $1.001^{b}$ & $1.000-1.002^{b}$ & 0.048 \\
\hline & & Maximum & $\mathrm{I} .00 \mathrm{I}$ & $1.000-1.003$ & 0.027 \\
\hline & & Change & 1.002 & $1.000-1.003$ & 0.020 \\
\hline & Nitric oxide & Minimum & $1.001^{\mathrm{b}}$ & $1.000-1.001^{b}$ & 0.011 \\
\hline & \multirow[t]{3}{*}{ Ozone } & Maximum & 0.998 & $0.996-0.999$ & 0.002 \\
\hline & & Mean & 0.998 & $0.996-1.000$ & 0.028 \\
\hline & & Change & 0.998 & $0.996-0.999$ & 0.003 \\
\hline & PMIO & Change & 1.005 & $1.001-1.009$ & 0.012 \\
\hline \multirow[t]{6}{*}{ One day before } & \multirow[t]{3}{*}{ Nitrogen dioxide } & Maximum & $1.001^{b}$ & $1.000-1.001^{b}$ & 0.010 \\
\hline & & Mean & $1.001^{\mathrm{b}}$ & $1.000-1.001^{\mathrm{b}}$ & 0.021 \\
\hline & & Change & $1.001^{b}$ & $1.000-1.001^{b}$ & 0.016 \\
\hline & \multirow[t]{3}{*}{ Ozone } & Maximum & 0.998 & $0.996-0.999$ & 0.001 \\
\hline & & Mean & 0.998 & $0.996-0.999$ & 0.011 \\
\hline & & Change & 0.998 & $0.997-0.999$ & 0.004 \\
\hline \multirow[t]{3}{*}{ Two days before } & \multirow[t]{3}{*}{ Ozone } & Maximum & 0.998 & $0.997-0.999$ & 0.002 \\
\hline & & Mean & 0.998 & $0.996-1.000$ & 0.019 \\
\hline & & Change & 0.998 & $0.997-0.999$ & 0.007 \\
\hline \multirow[t]{11}{*}{ Three days before } & \multirow[t]{2}{*}{ Carbon monoxide } & Maximum & 1.047 & $1.005-1.09 \mid$ & 0.029 \\
\hline & & Change & 1.053 & $1.007-1.102$ & 0.024 \\
\hline & \multirow[t]{3}{*}{ Nitric oxide } & Maximum & 1.001 & $1.000-1.001$ & 0.042 \\
\hline & & Medium & 1.001 & $1.000-1.002$ & 0.039 \\
\hline & & Change & 1.001 & $1.000-1.001$ & 0.043 \\
\hline & \multirow[t]{3}{*}{ Ozone } & Maximum & 0.998 & $0.997-0.999$ & 0.003 \\
\hline & & Mean & 0.997 & $0.996-0.999$ & 0.003 \\
\hline & & Change & 0.999 & $0.997-1.000$ & 0.031 \\
\hline & \multirow[t]{2}{*}{ PMIO } & Maximum & 1.007 & $1.001-1.013^{b}$ & 0.033 \\
\hline & & Change & 1.004 & $1.001-1.008$ & 0.022 \\
\hline & PM2.5 & Change & 1.011 & $1.000-1.021$ & 0.042 \\
\hline
\end{tabular}

${ }^{a}$ Mixed effect model with Poisson likelihood and log link, to account for centre-wise clustering. ${ }^{18}$ Models with and without quadratic terms were tested separately, to appraise the impact of non-linear effects (with the latter presented in the case of nominally significant $(p<0.05)$ results).

${ }^{\mathrm{b}}$ Quadratic term.

PMI0: particulate matter with a diameter between $2.5 \mu \mathrm{m}$ and $10 \mu \mathrm{m}$; PM2.5: particulate matter with a diameter less than $2.5 \mu \mathrm{m}$

impact of weather and pollutants on the risk of AMI in general, and some already on the risk of STEMI in particular, such that improvements in environment and pollution may directly lead to reductions in ageadjusted rates of coronary artery disease events. ${ }^{10,24-26}$ Indeed, CO, PM10 and PM2.5, among others, have already been linked to the risk of coronary events in several works. ${ }^{10,17,27,28}$ However, uncertainty persists on the real impact of such environmental features on cardiovascular risk, given the competing effects of different variables, the non-linear associations and the typical time lag between exposure and disease. We thus aimed at disentangling this complex scenario by appraising the impact of several pollutants and weather features on the risk of STEMI in two large urban Italian areas.
Briefly, we found that the risk of STEMI was strongly associated with several pollution and weather features. While causation cannot be directly inferred from our work, concentrations of CO, NOX, PM10, $\mathrm{O} 3$ and PM2.5 were all individually capable of predicting STEMI risk well before the adverse event. In particular, these features changed significantly as early as three days before the event, with increasing values being associated with an increased risk (with the notable exclusion of O3). Pollutant concentrations also predicted STEMI risk on a shorter term (i.e. two days later, one day later, or on the same day). In addition, NO also proved capable of significantly predicting STEMI risk, in a concordant fashion, albeit only one day before the event (yet also on the same day). On top of pollutants, temperature and atmospheric pressure 
were significantly associated with STEMI risk, even days before the adverse event. Yet, temperature, atmospheric pressure and, as stated above, $\mathrm{O} 3$, were inversely related to STEMI risk. Thus, colder days were the days of higher risk of STEMI, with concomitant lower pressures, lower $\mathrm{O} 3$ concentrations and worse pollution. The interplay with sun exposure remains a focus of intense research, whereas rainfall, albeit not proving as a significant and independent predictor in our study, is important given its role in impacting on pollution. ${ }^{29}$

Overall, these findings have major population and clinical implications. First, they confirm and expand prior works on the same topic, including detailed reports from the extensive data gathered by the United States Environmental Protection Agency. $8,16,30$ Most importantly, they challenge decision-makers and stakeholders working on population interventions and infrastructure planning on one hand, and clinicians and patients aiming at individualized care on the other hand. Interventions for environmental safety and weather improvement are direly needed to protect frail patients and populations at large. ${ }^{6,7}$ Focusing on a shorter term, adverse changes in environmental pollutants and weather features need to raise the alert and the responsiveness of emergency services, while cautioning patients in terms of pharmacologic therapy and avoidance of unnecessary untoward exposures. ${ }^{31-33}$

Strengths of our work are several, and include the carefully selected population, featuring only patients with STEMI admitted for primary PCI. Accordingly, case definition was based on both clinical and angiographic criteria, and not on discharge diagnoses, as done in the vast majority of prior studies on this topic. Indeed, STEMI is almost invariably due to occlusive or subocclusive atherothrombosis, defining a quite homogenous and high-risk clinical condition, at odds with the clinical category of non-STEMI, characterized by substantial clinical and pathophysiological heterogeneity.

Weaknesses of this work include the retrospective design, lack of direct estimates for catchment area and patients at risk, limited adjustment for confounders (e.g. per-patient ones such as comorbidities or socio-economic status), lack of penalization for multiple testing, and impossibility to focus on patient features thus enabling subgrouping of STEMI risk strata. As we did not rely on a universally inclusive population at risk, only independent association was appraised with statistical modelling, refraining from computing population attributable fraction. In addition, the link between STEMI occurrence and exposure can only be inferred by admission to one of the participating centres, as AMI leading to sudden cardiac death without hospital admission was not included in the data capturing system. Accordingly, only indirect validity for our results can be purported for sudden cardiac death or AMI not leading to emergency hospital admission. The apparent protective effect of $\mathrm{O} 3$ should be viewed in light of the correlation between this agent and other weather and environment features, as well as the heterogeneity and threshold effects already demonstrated for $\mathrm{O} 3{ }^{34}$ Thus, we look forward to formally confirming or disproving the present findings in an external validation cohort, possibly also testing the impact of other interacting features such as traffic blocks and mitigation efforts. Another useful analytical approach would be to appraise (as control or adjustment tool), an outcome which should not per se be associated with weather or pollution (for instance elective coronary procedures).

\section{Author contribution}

GB-Z and GF contributed equally to this work. GB-Z, GF and FV designed the study, handled data analysis and interpretation and drafted the manuscript. AG, EM, ADDG, AB, ADG, SC, MS, SS, VV, RC, GV, MBG, MPer, EC, SB, JC, MF, LR and FR participated in data collection, data analysis and interpretation and critically reviewed the manuscript for important intellectual content. All authors finally approved the manuscript.

\section{Declaration of conflicting interests}

The author(s) declared no potential conflicts of interest with respect to the research, authorship, and/or publication of this article.

\section{Funding}

The author(s) received no financial support for the research, authorship, and/or publication of this article.

\section{References}

1. Feigin VL, Roth GA, Naghavi M, et al.; Global Burden of Diseases, Injuries and Risk Factors Study 2013 and Stroke Experts Writing Group. Lancet Neurol 2016; 15 : 913-924.

2. Vidale S and Campana C. Ambient air pollution and cardiovascular diseases: From bench to bedside. Eur $J$ Prev Cardiol 2018; 25: 818-825.

3. Biondi-Zoccai G, Garmendia CM, Abbate A, et al. Atherothrombosis prevention and treatment with antiinterleukin-1 agents. Curr Atheroscler Rep 2020; 22: 4.

4. Nudi F, Schillaci O, Di Belardino N, et al. Temporal trends in the prevalence, severity, and localization of myocardial ischemia and necrosis at myocardial perfusion imaging after myocardial infarction. Am J Cardiol 2017; 120: 1238-1244.

5. Calcagno S, Dei Giudici A, Scappaticci M, et al. Air pollution, climate changes and cardiovascular diseases: A nightmare threesome! Minerva Cardioangiol, Epub 
ahead of print 26 February 2020. DOI: 10.23736/S00264725.20.05122-1

6. Kwon OK, Kim SH, Kang $\mathrm{SH}$, et al. Association of short- and long-term exposure to air pollution with atrial fibrillation. Eur J Prev Cardiol 2019; 26: 1208-1216.

7. Sun Z, Chen C, Xu D, et al. Effects of ambient temperature on myocardial infarction: A systematic review and meta-analysis. Environ Pollut 2018; 241: 1106-1114.

8. Biggeri A, Bellini $\mathrm{P}$ and Terracini B; Italian MISA Group. Meta-analysis of the Italian studies on shortterm effects of air pollution. Epidemiol Prev 2001; 25: $1-71$.

9. Tian Y, Liu H, Wu Y, et al. Ambient particulate matter pollution and adult hospital admissions for pneumonia in urban China: A national time series analysis for 2014 through 2017. PLoS Med 2019; 16: e1003010.

10. Claeys MJ, Rajagopalan S, Nawrot TS, et al. Climate and environmental triggers of acute myocardial infarction. Eur Heart J 2017; 38: 955-960.

11. Halonen JI, Zanobetti A, Sparrow D, et al. Associations between outdoor temperature and markers of inflammation: A cohort study. Environ Health 2010; 9: 9-42.

12. Halonen JI, Zanobetti A, Sparrow D, et al. Outdoor temperature is associated with serum HDL and LDL. Environ Res 2011; 111: 281-287.

13. Combes A and Franchineau G. Fine particle environmental pollution and cardiovascular diseases. Metabolism 2019; 100S: 153944.

14. Keatinge WR, Coleshaw SR, Cotter F, et al. Increases in platelet and red cell counts, blood viscosity, and arterial pressure during mild surface cooling: Factors in mortality from coronary and cerebral thrombosis in winter. $B M J$ 1984; 289: 1405-1408.

15. Keatinge WR, Coleshaw SR, Easton JC, et al. Increased platelet and red cell counts, blood viscosity, and plasma cholesterol levels during heat stress, and mortality from coronary and cerebral thrombosis. Am J Med 1986; 81: 795-800.

16. Argacha JF, Collart P, Wauters A, et al. Air pollution and ST-elevation myocardial infarction: A case-crossover study of the Belgian STEMI registry 2009-2013. Int $J$ Cardiol 2016; 223: 300-305.

17. Macchi C, Ferri N, Favero C, et al. Long-term exposure to air pollution raises circulating levels of proprotein convertase subtilisin/kexin type 9 in obese individuals. Eur $J$ Prev Cardiol 2019; 26: 578-588.

18. Versaci F, Biondi-Zoccai G, Giudici AD, et al. Climate changes and ST-elevation myocardial infarction treated with primary percutaneous coronary angioplasty. Int $J$ Cardiol 2019; 294: 1-5.

19. Versaci F, Biondi-Zoccai G, Sciarretta S, et al. Missed opportunities in cardiac arrest: The promise of $24 / 7$ ongoing on-site interventional cardiologist availability. J Am Coll Cardiol 2018; 71: 2492-2493.

20. WHO. Global ambient air quality database, https://www. who.int/airpollution/data/cities/en/ (2018, accessed 7 February 2020).
21. Frati G, Carnevale R, Nocella C, et al. Profiling the acute effects of modified risk products: Evidence from the SUR-VAPES (Sapienza University of Rome-Vascular Assessment of Proatherosclerotic Effects of Smoking) cluster study. Curr Atheroscler Rep 2020; 22: 8.

22. Ebi KL, Mills DM, Smith JB, et al. Climate change and human health impacts in the United States: An update on the results of the U.S. national assessment. Environ Health Perspect 2006; 114: 1318-1324.

23. Zhang $W$, Wang $H$, Zhang $X$, et al. Evaluating the contributions of changed meteorological conditions and emission to substantial reductions of PM2.5 concentration from winter 2016 to 2017 in Central and Eastern China. Sci Total Environ 2020; 716: 136892.

24. Zhan Z, Zhao Y, Pang S, et al. Temperature change between neighboring days and mortality in United States: A nationwide study. Sci Total Environ 2017; 585: 1152-1161.

25. Havenith G. Temperature regulation, heat balance and climatic stress. In: Kirch W, Menne B and Bertollini R (eds) Extreme weather events and public health responses. Berlin: Springer, 2005, pp.69-80.

26. Martinez-Nicolas A, Meyer M, Hunkler S, et al. Daytime variation in ambient temperature affects skin temperatures and blood pressure: Ambulatory winter/summer comparison in healthy young women. Physiol Behav 2015; 149: 203-211.

27. Huang K, Liang F, Yang X, et al. Long term exposure to ambient fine particulate matter and incidence of stroke: Prospective cohort study from the China-PAR project. BMJ 2019; 367: 16720.

28. Lelieveld J, Klingmüller $\mathrm{K}$, Pozzer $\mathrm{A}$, et al. Cardiovascular disease burden from ambient air pollution in Europe reassessed using novel hazard ratio functions. Eur Heart J 2019; 40: 1590-1596.

29. Oyama Y, Bartman CM, Bonney S, et al. Intense lightmediated circadian cardioprotection via transcriptional reprogramming of the endothelium. Cell Rep 2019; 28: 1471-1484.

30. Cheng J, Xu Z, Bambrick H, et al. The mortality burden of hourly temperature variability in five capital cities, Australia: Time-series and meta-regression analysis. Environ Int 2017; 109: 10-19.

31. Fiordelisi A, Piscitelli P, Trimarco B, et al. The mechanisms of air pollution and particulate matter in cardiovascular diseases. Heart Fail Rev 2017; 22: 337-347.

32. Sicard P, Khaniabadi YO, Perez S, et al. Effect of O3, PM10 and PM2.5 on cardiovascular and respiratory diseases in cities of France, Iran and Italy. Environ Sci Pollut Res Int 2019; 26: 32645-32665.

33. Lelieveld $\mathbf{J}$ and Münzel T. Air pollution, the underestimated cardiovascular risk factor. Eur Heart J 2020; 41: 904-905.

34. Vicedo-Cabrera AM, Sera F, Liu C, et al. Short term association between ozone and mortality: Global two stage time series study in 406 locations in 20 countries. BMJ 2020; 368: m108. 